\title{
The Association Between Doctor and Pharmacy Shopping and Self-Reported Misuse and Abuse of Prescription Opioids: A Survey Study
}

This article was published in the following Dove Press journal: Journal of Pain Research

Judith J Stephenson $\mathbb{D}^{\prime}$

M Soledad Cepeda (iD ${ }^{2}$

Jie Zhang ${ }^{3,4}$

Jade Dinh (D) ${ }^{4}$

Kelsey Hall ${ }^{4}$

Daina B Esposito ${ }^{4-6}$

David M Kern (D) ${ }^{2}$

'Scientific Affairs, HealthCore, Inc, Wilmington, DE, USA; ${ }^{2}$ Epidemiology, Janssen Research and Development, Titusville, NJ, USA; ${ }^{3}$ Center for Observational Research, Amgen Inc., Thousand Oaks, CA, USA; ${ }^{4}$ Safety and Epidemiology, HealthCore, Inc., Wilmington, DE, USA; ${ }^{5}$ Ciconia, Inc, Westford, MA, USA; ${ }^{6}$ Epidemiology, Boston University, Boston, MA, USA

Correspondence: Judith J Stephenson HealthCore, Inc., 123 Justison Street, Suite 200, Wilmington, DE 1980I, USA $\mathrm{Tel}+\mid$ 302-230-2|42

Email jstephenson@healthcore.com
Background/Rationale: Little is known about the reasons for visiting multiple doctors/ pharmacies, known as doctor/pharmacy shopping, to obtain opioids.

Objective: To investigate patients' self-reported reasons for doctor/pharmacy shopping and assess whether doctor/pharmacy shopping behavior can be used as a surrogate measure of opioid abuse/misuse.

Methods: We conducted a cross-sectional web-based survey among adult patients with $\geq 2$ pharmacy claims for immediate-release or extended-release/long-acting opioids between 7/1/ 2015 and 12/31/2016, identified from a large United States (US) commercial claims database. Patients were classified into no, mild, moderate, or severe shopping categories based on their claims. Reasons for doctor/pharmacy shopping and opioid abuse/misuse were determined from patient responses to the Prescription Opioid Misuse and Abuse Questionnaire.

Results: A random sample of 10,081 patients was invited to participate in the survey and 1085 (11\%) completed surveys. The most frequently reported reasons for doctor/pharmacy shopping were convenience, availability, price, and multiple morbidities requiring pain management. Among patients in the no, minimal, moderate, and severe shopping categories, only $7.8 \%, 8.5 \%, 11.8 \%$ and $12.6 \%$ reported opioid abuse/misuse, respectively.

Conclusion: In this commercially-insured population, patient-reported reasons for doctor/ pharmacy shopping do not suggest opioid abuse/misuse. Less than $15 \%$ of patients with shopping behavior in the past 3 months reported any reasons attributable to opioid abuse/ misuse, indicating that shopping behavior in this population may not be a good surrogate for abuse/misuse.

Keywords: doctor/pharmacy shopping, prescription opioid, abuse and misuse

\section{Introduction}

Despite a decline in the amount of opioids prescribed nationally since 2011, fueled by a significant increase in overdose rate involving illicitly manufactured fentanyl, the number of deaths due to drug overdose, including prescription opioids, remains a significant public health issue. ${ }^{1-4}$ Doctor and pharmacy shopping (also referred to as "shopping behavior" throughout) defined as visiting multiple prescribers and pharmacies over a specific period of time to obtain scheduled drugs, has been identified as both an important means to acquire these drugs and an indicator for misuse and abuse. ${ }^{5-7}$

A number of claims-based studies has provided insights into doctor/pharmacy shopping, including an association with younger age, concurrent use of other 
controlled substances, a diagnosis of pain, and diagnosis of mental disorders. ${ }^{8-10}$ Patients who exhibited shopping behavior were more likely to travel long-distances to fill their opioid prescriptions from more than one state $(20 \%$ and 4\%) and to pay fully in cash than those who did not exhibit shopping behavior (44\% and 18\%). ${ }^{11,12}$ Doctor/ pharmacy shopping has also been associated with opioid abuse, overdose, opioid related hospital admissions, and drug-related death; however, using claims-determined definitions of doctor/pharmacy shopping as an indicator of opioid misuse or abuse may misidentify patients who have justifiable reasons for visiting multiple doctors or pharmacies. $^{6,8,9,13}$

Because studies of doctor/pharmacy shopping have traditionally relied on data from insurance claims or prescription drug monitoring programs, there is limited information from the patient perspective. To fill this gap and to meet a Food and Drug Administration (FDA) postmarketing requirement for extended-release and longacting opioid (ER/LA) analgesics, the present study was conducted to investigate the reasons patients visited multiple prescribers and/or pharmacies to obtain prescription opioids and to assess the association between doctor/pharmacy shopping behavior and self-reported misuse and abuse.

\section{Materials and Methods Overview of Study Design}

We conducted a cross-sectional web-based survey among eligible patients identified from their administrative claims data. The sample population consisted of patients who had at least two dispensings of prescription opioids during the 18-month patient identification period from 7/1/2015 to 12/31/2016 (inclusive) and satisfied all inclusion/exclusion criteria. A random sample of eligible patients, stratified by their claims-determined doctor/pharmacy shopping category, was selected and invited to participate in the survey. Survey respondents completed the Prescription Opioid Misuse and Abuse Questionnaire (POMAQ) that assessed current and past behaviors related to prescription opioid misuse and abuse as well as reasons for doctor/pharmacy shopping. ${ }^{14}$

\section{Data Source and Study Population}

The HealthCore Integrated Research Database (HIRD), a large administrative claims database that contains longitudinal medical and pharmacy claims from 14 United
States (US) health plans, was utilized as the sampling frame to identify the eligible survey population. Eligible patients were required to satisfy the following inclusion criteria: 1) $\geq$ two dispensings of any immediate release (IR) or ER/LA prescription opioid on different dates during the patient identification period from $7 / 1 / 2015$ to 12 / $31 / 2016$; 2) $\geq 18$ years of age on the date of the first IR or ER/LA dispensing during the patient identification period; 3) commercial health insurance with continuous enrollment and medical and pharmacy benefits during the patient identification period; and 4) eligible to be contacted for survey (eg, availability of email and/or physical address, no claims indicating receipt of care at a longterm care facility, not on any Do-Not-Call lists and no claims suggestive of drug or substance abuse). Patients with claims suggestive of drug or substance abuse were excluded to comply with Title 42 of the Code of Federal Regulations Part 2 (42 CFR Part 2) Rule which protects the privacy of individuals undergoing substance and alcohol abuse treatment.

Eligible patients were classified into one of four claims-determined doctor/pharmacy shopping categories: no shopping, minimal shopping, moderate shopping, and severe shopping, based on the number of doctors and pharmacies they visited to obtain prescription opioids as determined from their pharmacy claims during the patient identification period. The algorithm used to define the doctor/pharmacy shopping categories was validated in a separate study conducted to satisfy the same postmarketing requirement and is presented in Table $1 .{ }^{15}$

A stratified random sample of eligible patients was selected and invited to participate in the survey with a targeted recruitment goal of having at least 271 patients with a completed survey in each shopping category. The goal was determined a priori to ensure that there was sufficient statistical power to detect a trend in the proportion of patients with the study outcome across the doctor/ pharmacy shopping categories using the CochranArmitage test. ${ }^{16,17}$ In order to increase the response rate, a multi-method three-stage approach to recruitment was implemented utilizing both emails and mailed letters. ${ }^{18}$ Patients who responded to the survey invitation and gave electronic consent were asked screening questions (ie, validation of name and date of birth and confirmation of prescription opioid use in the last 12 months) prior to starting the survey; those who failed any of the screening questions or did not provide consent were excluded from survey participation. 
Table I Claims-Determined Doctor/Pharmacy Shopping Category Definitions

\begin{tabular}{|c|c|}
\hline Category & Definition \\
\hline $\begin{array}{l}\text { No Doctor/Pharmacy } \\
\text { Shopping }\end{array}$ & $\begin{array}{l}\text { Visited during I8-month period: } \\
\text { - I prescriber (regardless of number of } \\
\text { pharmacies) OR } \\
\text { - I pharmacy (regardless of number of } \\
\text { prescribers) OR } \\
\text { - } 2 \text { prescribers and } 2 \text { pharmacies }\end{array}$ \\
\hline $\begin{array}{l}\text { Minimal Doctor/Pharmacy } \\
\text { Shopping }\end{array}$ & $\begin{array}{l}\text { Visited during 18-month period: } \\
\text { - } 2 \text { prescribers AND >2 pharmacies } \\
\text { OR } \\
\text { - } 3 \text { or } 4 \text { prescribers AND } 2 \text { pharmacies }\end{array}$ \\
\hline $\begin{array}{l}\text { Moderate Doctor/ } \\
\text { Pharmacy Shopping }\end{array}$ & $\begin{array}{l}\text { Visited during } 18 \text { month period: } \\
\text { - } 3 \text { or } 4 \text { prescribers AND }>2 \text { pharma- } \\
\text { cies OR } \\
\text { - }>4 \text { prescribers AND } 2 \text { pharmacies }\end{array}$ \\
\hline $\begin{array}{l}\text { Severe Doctor/Pharmacy } \\
\text { Shopping }\end{array}$ & $\begin{array}{l}\text { Visited during } 18 \text { month period: } \\
->4 \text { prescribers AND }>2 \text { pharmacies }\end{array}$ \\
\hline
\end{tabular}

\section{Assessment of Prescription Opioid Abuse and/or Misuse}

Prescription opioid abuse and/or misuse was determined from the Prescription Opioid Misuse and Abuse Questionnaire (POMAQ), a patient reported outcome measure that was designed to assess and measure current and past patient behaviors related to prescription opioid misuse and abuse. The goal of the POMAQ is to assess the presence of specific behaviors related to the misuse and abuse of prescription opioids. A behavior or combination of behaviors are identified as opioid misuse or abuse (or both) based upon how the patient responds to reasons about the intention of the specific behavior. ${ }^{14}$ The definitions of misuse and abuse are based on those in the Analgesic, Anesthetic, and Addiction clinical trials, Translation, Innovations, Opportunities, and Networks (ACTTION) review. ${ }^{19}$ Abuse is defined as any intentional, nontherapeutic use of a drug product or substance, repeatedly or sporadically, for the purpose of achieving a desirable psychological or physiological effect. Examples of abuse include taking a drug to feel high or stoned or to get a better feeling of high or needing more drug than one doctor would prescribe. Misuse is defined as any intentional therapeutic use of a drug in an inappropriate way including outside label directions or other than prescribed or directed by a health-care provider. Examples of misuse include using a drug for a condition that is different from the condition for which the drug was prescribed, taking more drugs than prescribed, or taking the drug at different dosing intervals than prescribed. Misuse excludes those events that meet the definition of abuse.

Patients were identified as opioid misusers and/or abusers based on their responses to the 19 POMAQ behavior questions. The POMAQ questions follow the same format and refer to three time periods: the past year, the past 3 months and the past 1 month. All attributions of behaviors as misuse or abuse are based on an assessment of the past 3 months. Questions start by determining whether the behavior occurred in the past year. This question is used as a screening question for the behavior and is followed by determining whether the behavior occurred in the past 3 months. If the behavior occurred in the past 3 months, patients were then asked to identify their reason(s) for the behavior from a pre-specified list of reasons or specify an open-ended reason not on the list. This shorter time period was used to facilitate a shorter recall period for determining the intent behind the behaviors. A 1-month question was used with follow-up questions dealing with the frequency of a specific behavior to make it easier for patients to remember the number of times a behavior occurred.

Three outcomes were evaluated in the study: 1) any abuse with or without misuse in the past 3 months, referred to as "abuse with/without misuse"; 2) any misuse with or without abuse in the past 3 months, referred to as "misuse with/without abuse"; and 3) abuse or misuse in the past 3 months, referred to as "abuse or misuse".

Patients' doctor shopping and/or pharmacy shopping behaviors are considered as misuse and/or abuse based on the occurrence of the behavior in the past 3 months and an endorsement of at least one reason attributable to misuse and/or abuse during that time period. In order to be considered an opioid abuser and/or misuser based only on the basis of doctor shopping behavior, patients have to respond "Yes" or "I am not sure" to the question that asks them whether they had visited more than 1 doctor or health-care provider to get more prescription opioid pain medication in the past year, followed by "Yes" to the question that they had visited more than 1 doctor or health-care provider to get more prescription opioid pain medication in the past 3 months. Finally, from the list of 12 pre-specified reasons and an open-ended other specify reason, the patient has to endorse at least 1 reason that is attributable to misuse and/or 1 reason that is attributable to abuse and/or write in some other reason that could be coded as attributable to either abuse, misuse, or neither. An example of a doctor shopping 
misuse reason is "I wanted to make sure I had enough opioid pain medication in case I needed it"; an example of an abuse reason is "I wanted to get more opioid pain medication to get high on"; and an example of a reason that cannot be attributed to either misuse or abuse is "My insurance, employment or place of residence changed and I had to change my doctor".

In a similar way, pharmacy shopping behavior was evaluated. In order to be considered an opioid abuser and/or misuser based only on their pharmacy shopping behavior, patients have to respond "Yes" or "I am not sure" to the question that askes them whether they had gone to more than 1 pharmacy to obtain their prescription opioid pain medication in the past year, followed by "Yes" to the question that they had gone to more than 1 pharmacy to obtain their prescription opioid pain medication in the past 3 months. Finally, from the list of 11 pre-specified reasons and an openended other specify reason, the patient has to endorse at least 1 reason attributable to misuse and/or 1 reason attributable to abuse and/or write in some other reason that could be coded as attributable to either abuse, misuse, or neither. An example of a pharmacy shopping misuse reason is "I needed more opioid pain medication to treat my pain"; an example of an abuse reason is "I wanted to get more opioid pain medication and did not want to get caught"; and an example of a reason that cannot be attributed to either misuse or abuse is "I use several different pharmacies for convenience".

A patient is considered someone who misuses and/or abuses opioid pain medications if, across all POMAQ behaviors, the patient reports the occurrence of at least one behavior in the past 3 months and indicates at least one reason attributable to misuse and/or abuse.

\section{Assessment of Patient Characteristics}

Patient characteristics were determined from both claims and the survey. Claims-determined characteristics included age (categorized: 18-34, 35-49, 50-64, 65 years and over), gender, geographic region of residence (categorized based on US census regions: Northeast, South, Midwest, West), comorbid conditions (diagnosis of pain and select psychiatric conditions), prescription opioid use (number of opioid dispensings, total duration of use, daily dose standardized to morphine milligram equivalent [MME], and type of opioid use [categorized: IR only, ER/LA only, IR and ER/LA]), use of other prescription medications with abuse potential, and all-cause health service utilization (number of inpatient visits, number of emergency room [ER] visits, number of outpatient visits, number of classes of prescription medications used). Age, gender, and geographic region of residence were assessed on the date of the first IR or ER/LA dispensing during the 18month patient identification period from $7 / 1 / 2015$ to $12 / 31$ / 2016 and the remaining characteristics were determined using claims data from the entire 18-month patient identification period. Additional demographic characteristics that were determined from the patient survey were race/ethnicity, education, marital status, employment status, and household income.

To evaluate the potential impact of social desirability bias on survey response, the Marlowe-Crowne Social Desirability Scale - Short Form was included in the web-based survey. ${ }^{20}$ This 13-item true/false scale is intended to assess the respondent's desire to project a socially desirable image, with a higher score indicating a greater tendency to report socially desirable information. Social desirability measured using the Marlowe-Crowne scale has been shown to impact reporting of substance abuse in previous research. ${ }^{21}$

\section{Data Analysis}

We described the selection of the study population showing attrition from all patients with at least two opioid dispensings during the 18 -month patient identification period from $7 / 1 / 2015$ to $12 / 31 / 2016$ to those who satisfied all the inclusion/exclusion criteria, to those who were randomly selected and invited to participate in the survey, and ultimately to those who completed the survey. The number of patients remaining at each step was calculated, and stratified by doctor/pharmacy shopping category.

We calculated descriptive statistics (eg, mean and standard deviation [SD], median and interquartile range [IQR], number and percent as applicable) for patient characteristics determined from their claims and the survey. These descriptive statistics were calculated separately among patients who completed the survey and among patients who satisfied all the inclusion/exclusion criteria, stratified by doctor/pharmacy shopping category. In addition, these statistics were also calculated among patients who were invited to participate in but did not complete the survey.

For each outcome ("abuse with/without misuse", "misuse with/without abuse", "abuse or misuse"), we calculated the number and percentage of patients with each outcome across the claims-determined doctor/pharmacy shopping categories from no shopping to severe shopping. The CochranArmitage test for trend was used to assess whether the observed trend was statistically significant. Logistic regression models were used to assess the association between claims-determined doctor/pharmacy shopping categories 
and each of the three self-reported outcomes: "abuse with/ without misuse" versus no abuse or misuse, "misuse with/ without abuse" versus no abuse or misuse, and "abuse or misuse" versus no misuse or abuse. Both unadjusted and adjusted analyses were performed, to control for potential confounding and to evaluate the contribution of the doctor/ pharmacy shopping categories and covariates in relation to the outcomes. In each model, we compared minimal, moderate, and severe shopping categories to the no shopping category. The following steps were taken to select and retain covariates in the adjusted model, given the expected small number of patients experiencing the outcomes. First, we assessed whether each covariate was associated with the outcome and retained those that had a p-value $<0.10$. The following covariates were evaluated for inclusion: age, gender, geographic region of residence, type of opioid used, average daily opioid dose, use of other drugs with abuse potential, history of psychiatric comorbidities, and type of pain diagnosis. We then included all covariates identified in the previous step in one regression model that also included the doctor/pharmacy shopping category. Next, we performed manual backward elimination retaining covariates using the $\mathrm{p}<0.10$ cut-off. In addition, we retained covariates if their removal resulted in a $>10 \%$ change in any of the odds ratios (ORs) between doctor/pharmacy shopping category and the outcome.

To evaluate the potential impact of social desirability bias self-reported outcomes, we categorized patients into low, medium, and high social desirability groups based on the tertile of their social desirability score, calculated the proportion of patients in each doctor/pharmacy shopping category and the proportion of patients who self-reported the study outcomes within each social desirability group, and assessed whether self-reported social desirability was associated with doctor/pharmacy shopping and with the study outcomes using a Chi-square test.

Finally, to provide information on patients who were excluded from participating in the survey due to the presence of claims indicative of drug/substance abuse, we compared the proportion of patients in each of the doctor/pharmacy shopping category between those who were eligible to participate in the study and those who had claims indicative of drug/substance abuse and the associated odds ratio.

\section{Human Subject Protection}

As protected health information (PHI) was required in the conduct of this study, a Health Insurance Portability and
Accountability Act of 1996 (HIPAA) Waiver of Authorization was applied for and obtained from the New England Institutional Review Board (NEIRB) prior to any PHI being identified. In addition, a Certificate of Confidentiality was obtained from the National Institutes of Health to ensure and assure participants of the protection of their privacy. The Certificate allows researchers to legally refuse to disclose information that may identify study participants in any federal, state, or local civil, criminal, administrative, legislative or other proceedings. Participants who completed the survey received a $\$ 50$ Amazon gift card to reimburse them for their time spent completing the survey.

\section{Results}

We identified a total of 320,753 patients who had at least two dispensings of IR or ER/LA opioids during the 18month patient identification period from $7 / 1 / 2015$ to 12 / $31 / 2016$. Forty percent $(n=129,650)$ of these patients met all of inclusion/exclusion criteria and were eligible to participate in the survey. A stratified random sample of 10,081 patients was selected across the four doctor/pharmacy shopping categories and invited to participate in the study via email and/or letter. Of those invited, $19.0 \%$ $(n=1,916)$ accessed the link for the web-based survey, including $566(5.6 \%)$ who agreed to participate in the survey but failed additional screening questions, 215 $(2.1 \%)$ who refused to participate or did not complete the survey, and $50(0.5 \%)$ who accessed the link after the recruitment goal was met and survey was closed. The remaining 1,085 participants completed the survey, meeting the target of having at least 271 patients with completed surveys in each doctor/pharmacy shopping category. The overall response rate was 19.0\% (number accessed the link $[n=1,916] /$ number invited to participate in the survey $[n=10,081]$ ) and the cooperation rate (number of completed surveys $[n=1085] /$ number accessed the link and passed the screening questions $[n=1,300])$ was $83.5 \%$. Detailed data on the sample identification are presented in Figure 1 and the strategy and steps taken to recruit survey participants have been described in detail. ${ }^{18}$

The distribution of select patient characteristics of the 1,085 respondents who completed the survey and the 129,650 patients who were eligible to participate in the survey are presented in Table 2, stratified by doctor/ pharmacy shopping category. Patients who completed the survey were similar to those in the original sample except that they were more likely to be female and to have a psychiatric diagnosis. Those in the severe shopping 


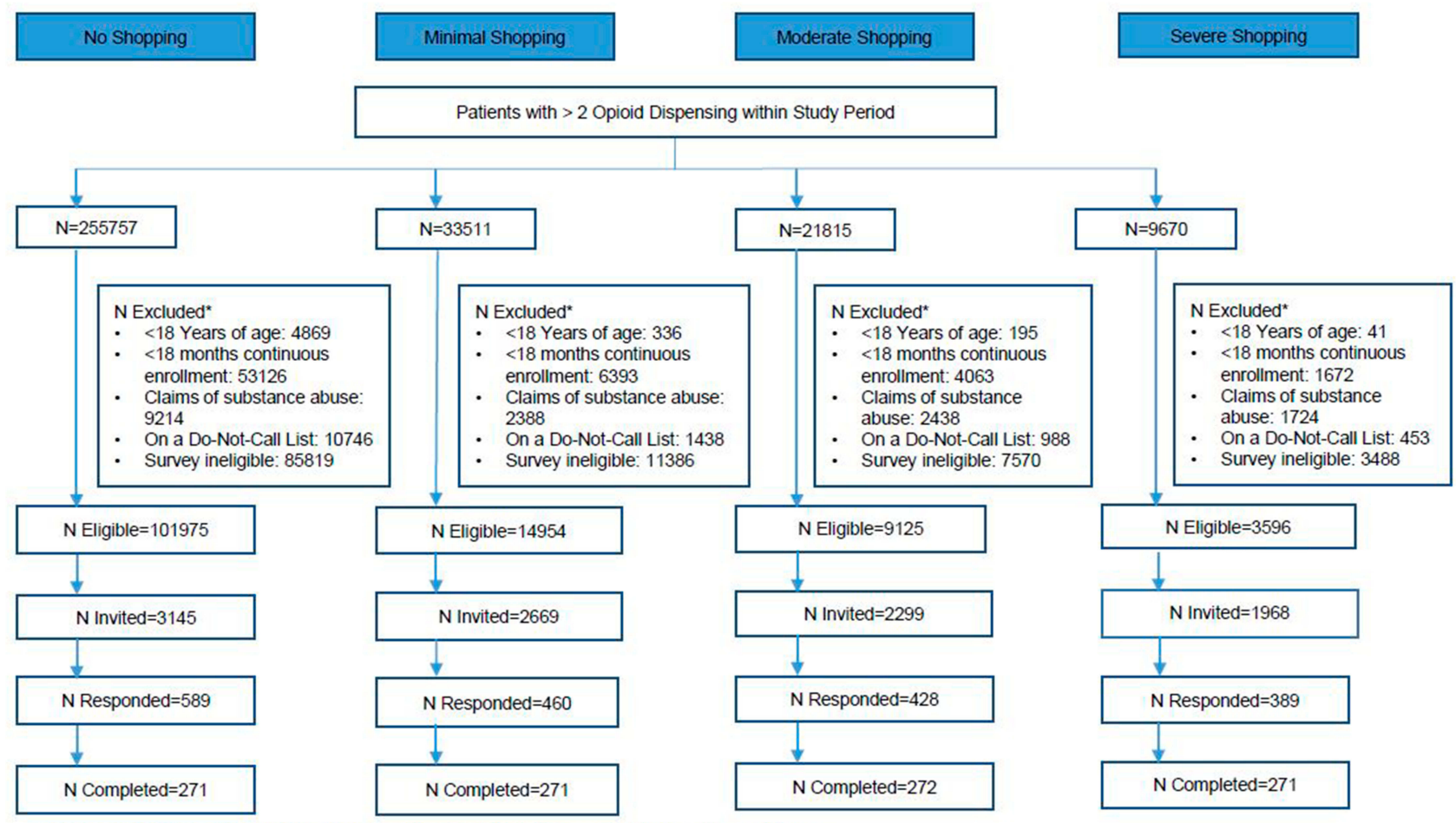

${ }^{*}$ Number excluded are not sequential and include overlaps (patients satisfy multiple exclusion criteria)

Figure I Sample identification.

category were younger, more likely to be female, less likely to be employed (full or part-time), had fewer years of education, and utilized more health services in general compared to those in the no shopping category. Patients with shopping behavior were also more likely to have a pain diagnosis, psychiatric condition, or to have used other medications with abuse potential. Among patients who were invited to participate in the survey, a comparison of patient characteristics between those who completed the survey and those who did not is presented in Table 3.

Over the 18-month patient identification period from $7 /$ $1 / 2015$ to $12 / 31 / 2016$, the median number of opioid prescribers and pharmacies visited to obtain prescription opioids increased from 1.6 prescribers and 1.5 pharmacies in the no shopping category to 6.4 prescribers visited and 4.0 pharmacies in the severe shopping category among survey respondents (Table 2). Among patients who reported visiting more than 1 doctor or pharmacy in the most recent 3 months prior to their survey date, the most frequent reasons reported for visiting multiple pharmacies included using "visited several different pharmacies for convenience", which was reported by $59.1 \%$ of those in the severe shopping category, followed by "regular pharmacy did not have enough of opioid pain medications", and visiting multiple pharmacies to "get the best prices". The most frequent reasons reported for visiting multiple doctors included "see different healthcare providers for different health problems so I ask for an opioid prescription when seeing each healthcare provider", "doctor does not understand my pain level", "my doctor thinks I may be faking my pain", and "needed more opioid pain medications to treat my pain than one doctor would give me". Very few patients reported reasons explicitly suggestive of prescription opioid misuse and/or abuse, such as wanting "more opioid pain medications to get high on" (Table 4).

Among the 1,085 survey respondents, 55 (5.1\%), 87 $(8.0 \%)$, and $110(10.1 \%)$ patients were considered as "abuse with/without misuse", "misuse with/without abuse", and "abuse or misuse", respectively. The percentage of patients with "misuse with/without abuse" increased as the severity of shopping category increased from $5.7 \%$ to $11.9 \%$ (Table 5) and the trend was statistically significant (p for trend: 0.006). Similarly, for "abuse or misuse", the percentage increased monotonically across the doctor/pharmacy shopping categories from $7.8 \%$ to $12.6 \%$ (p for trend: 0.031 ). For the "abuse with/without misuse" outcome, however, a trend was not observed. Doctor/pharmacy shopping behavior was associated with an increased risk of "misuse 
Table 2 Distribution of Baseline Characteristics, Among Patients Eligible to Participate in the Survey and Survey Respondents, by Doctor/Pharmacy Shopping Category

\begin{tabular}{|c|c|c|c|c|c|c|c|c|}
\hline & \multicolumn{4}{|c|}{ Patients Who Completed Survey } & \multicolumn{4}{|c|}{ Patients Eligible to Participate in Survey } \\
\hline & $\begin{array}{l}\text { No } \\
\text { Shopping }\end{array}$ & $\begin{array}{l}\text { Minimal } \\
\text { Shopping }\end{array}$ & $\begin{array}{l}\text { Moderate } \\
\text { Shopping }\end{array}$ & $\begin{array}{l}\text { Severe } \\
\text { Shopping }\end{array}$ & $\begin{array}{l}\text { No } \\
\text { Shopping }\end{array}$ & $\begin{array}{l}\text { Minimal } \\
\text { Shopping }\end{array}$ & $\begin{array}{l}\text { Moderate } \\
\text { Shopping }\end{array}$ & $\begin{array}{l}\text { Severe } \\
\text { Shopping }\end{array}$ \\
\hline & $N=27 \mid$ & $\mathbf{N}=\mathbf{2 7} \mid$ & $N=272$ & $N=27 I$ & $N=101,975$ & $N=14,954$ & $N=9 \mid 25$ & $N=3596$ \\
\hline \multicolumn{9}{|l|}{ Demographics } \\
\hline Age in years, mean $\pm S D$ & $46 \pm 11.4$ & $47 \pm 11.1$ & $45 \pm 11.7$ & $42 \pm 10.1$ & $48 \pm 12.8$ & $47 \pm 12.3$ & $47 \pm 12.3$ & $45 \pm 11.8$ \\
\hline Female, $n, \%$ & $17 \mid, 63.1$ & $168,62.0$ & $166,61.0$ & $183,67.5$ & $53,535,52.5$ & $8037,53.7$ & $5083,55.7$ & $2135,59.4$ \\
\hline White, non-Hispanic, n, \% & $244,90.0$ & $243,90.0$ & $243,89.7$ & $244,90.0$ & & & & \\
\hline \multicolumn{9}{|l|}{ Education, $n, \%^{a}$} \\
\hline High School or Less & $44,16.2$ & $55,20.3$ & $59,21.7$ & $57,21.0$ & & & & \\
\hline Some College & $101,37.3$ & $126,46.5$ & $120,44.1$ & $115,42.4$ & & & & \\
\hline College or More & $125,46.1$ & $89,32.8$ & $93,34.2$ & $99,36.5$ & & & & \\
\hline \multicolumn{9}{|l|}{ Marital Status, n, \% } \\
\hline Married & $167,61.6$ & $162,59.8$ & $168,61.8$ & $170,62.7$ & & & & \\
\hline Single & $50,18.5$ & $61,22.5$ & $49,18.0$ & $52,19.2$ & & & & \\
\hline Other & $54,19.9$ & $48,17.7$ & $55,20.2$ & $49,18.1$ & & & & \\
\hline Employed, Full or Part time, n, \% & $230,84.9$ & $209,77.1$ & $204,75.0$ & 197, 72.7 & & & & \\
\hline \multicolumn{9}{|l|}{ Income, $n, \%$} \\
\hline$<\$ 50,000$ & $74,27.3$ & $88,32.5$ & $95,34.9$ & $77,28.4$ & & & & \\
\hline$\$ 50,000-74,999$ & $56,20.7$ & $59,21.8$ & $50,18.4$ & $68,25.1$ & & & & \\
\hline$\$ 75,000-99.999$ & $49,18.1$ & $50,18.5$ & $38,14.0$ & $35,12.9$ & & & & \\
\hline$\$ 100,000$ or more & $82,30.3$ & $66,24.3$ & $75,27.6$ & $77,28.4$ & & & & \\
\hline Do not Know & $10,3.7$ & $8,3.0$ & $14,5.2$ & $14,5.2$ & & & & \\
\hline \multicolumn{9}{|l|}{ Pain Diagnosis } \\
\hline Abdominal Pain, $n, \%$ & $52,19.2$ & $91,33.6$ & $104,38.2$ & $143,52.8$ & $20,328,19.9$ & $4545,30.4$ & $3366,36.9$ & $1770,49.2$ \\
\hline Arthritis Pain, n, \% & $61,22.5$ & $76,28.0$ & $99,36.4$ & $89,32.8$ & $20,68 I, 20.3$ & $4300,28.8$ & $3005,32.9$ & |35|, 37.6 \\
\hline Back Pain, n, \% & $103,38.0$ & $130,48.0$ & $158,58.1$ & $181,66.8$ & $31,350,30.7$ & $6777,45.3$ & $4793,52.5$ & $2361,65.7$ \\
\hline Chronic Pain, $\mathrm{n}, \%$ & $54,19.9$ & $77,28.4$ & $108,39.7$ & $137,50.6$ & $15,762,15.5$ & $4253,28.4$ & $3424,37.5$ & $1832,50.9$ \\
\hline Headache, n, \% & $48,17.7$ & $62,22.9$ & $73,26.8$ & $102,37.6$ & $12,829,12.6$ & $2840,19.0$ & $2125,23.3$ & $|15|, 32.0$ \\
\hline Neuropathic Pain, n, \% & $45,16.6$ & $75,27.7$ & $83,30.5$ & $95,35.1$ & $14,143,13.9$ & $3360,22.5$ & $2513,27.5$ & 136437.9 \\
\hline \multicolumn{9}{|l|}{ Psychiatric Diagnosis } \\
\hline Anxiety, n, \% & $65,24.0$ & $79,29.2$ & $89,32.7$ & $127,46.9$ & $17,686,17.3$ & $3901,26.1$ & $2888,31.6$ & $1540,42.8$ \\
\hline Depression, n, \% & $47,17.3$ & $68,25.1$ & $80,29.4$ & $97,35.8$ & $13,602,13.3$ & $3125,20.9$ & $2343,25.7$ & $1170,32.5$ \\
\hline \multicolumn{9}{|l|}{ Opioid Use During the I8-Month } \\
\hline $\begin{array}{l}\text { Period from } 7 / 1 / 15 \text { to }|2 / 3| / 16 \\
N \text { of Opioid Prescribers, mean } \pm S D\end{array}$ & $1.6 \pm 0.5$ & $3.0 \pm 0.7$ & $4.1 \pm 1.4$ & $6.4 \pm 2.1$ & $1.7 \pm 0.6$ & $3.0 \pm 0.7$ & $4.1 \pm 1.5$ & $6.6 \pm 2.4$ \\
\hline $\begin{array}{l}\mathrm{N} \text { of Pharmacies Opioid Fills, mean } \\
\pm S D\end{array}$ & $1.5 \pm 0.8$ & $2.3 \pm 0.7$ & $3.2 \pm 1.2$ & $4.0 \pm 1.4$ & $1.4 \pm 0.6$ & $2.3 \pm 0.7$ & $3.0 \pm 1.0$ & $4.0 \pm 1.4$ \\
\hline $\begin{array}{l}\mathrm{N} \text { of Opioid Dispensings, median, } \\
\text { IQR }\end{array}$ & $2.0,2.0$ & $4.0,6.0$ & $7.0,9.0$ & $11.0,11.0$ & $2.0,1.0$ & $4.0,5.0$ & $6.0,9.0$ & $12.0,12.0$ \\
\hline $\begin{array}{l}\text { Duration of Opioid Use, median, } \\
\text { IQR }\end{array}$ & $0.6,1.9$ & $1.3,5.9$ & $2.5,9.0$ & $4.1,9.3$ & $0.4,1.1$ & $1.2,3.8$ & $2.0,8.3$ & $4.8,10.6$ \\
\hline $\begin{array}{l}\text { Opioid Daily Dose (MME/day), } \\
\text { median, IQR }\end{array}$ & $33.1,25.5$ & $34.4,22.6$ & $36.9,26.0$ & $33.1,20.0$ & $33.2,22.1$ & $34.4,22.2$ & $34.8,22.5$ & $33.6,21.2$ \\
\hline \multicolumn{9}{|l|}{ Use of Other Medications } \\
\hline Benzodiazepine, n, \% & $54,19.9$ & $75,27.7$ & $102,37.5$ & $120,44.3$ & $20,391,20.0$ & $4482,30.0$ & $3182,34.9$ & $1629,45.3$ \\
\hline Sleep Aid, n, \% & $27,10.0$ & $28,10.3$ & $51,18.8$ & $63,23.2$ & $8751,8.6$ & $1889,12.6$ & $1365,15.0$ & $696,19.4$ \\
\hline
\end{tabular}


Table 2 (Continued).

\begin{tabular}{|c|c|c|c|c|c|c|c|c|}
\hline & \multicolumn{4}{|c|}{ Patients Who Completed Survey } & \multicolumn{4}{|c|}{ Patients Eligible to Participate in Survey } \\
\hline & $\begin{array}{l}\text { No } \\
\text { Shopping }\end{array}$ & $\begin{array}{l}\text { Minimal } \\
\text { Shopping }\end{array}$ & $\begin{array}{l}\text { Moderate } \\
\text { Shopping }\end{array}$ & $\begin{array}{l}\text { Severe } \\
\text { Shopping }\end{array}$ & $\begin{array}{l}\text { No } \\
\text { Shopping }\end{array}$ & $\begin{array}{l}\text { Minimal } \\
\text { Shopping }\end{array}$ & $\begin{array}{l}\text { Moderate } \\
\text { Shopping }\end{array}$ & $\begin{array}{l}\text { Severe } \\
\text { Shopping }\end{array}$ \\
\hline & $\mathbf{N}=\mathbf{2 7}$ I & $\mathbf{N}=\mathbf{2 7} \mid$ & $\mathrm{N}=\mathbf{2 7 2}$ & $\mathbf{N}=\mathbf{2 7} \mid$ & $N=101,975$ & $N=14,954$ & $N=9 \mid 25$ & $N=3596$ \\
\hline Amphetamines, $\mathrm{n}, \%$ & II, 4.1 & $27,10.0$ & $26,9.6$ & $20,7.4$ & $3983,3.9$ & $855,5.7$ & $607,6.7$ & $304,8.5$ \\
\hline \multicolumn{9}{|l|}{$\begin{array}{l}\text { Health Services Utilization During the } \\
\text { 18-Month Period from } 7 / 1 / 15 \text { to } 12 / \\
31 / 16\end{array}$} \\
\hline $\mathrm{N}$ of Physician Office Visit, mean \pm SD & $12.8 \pm 1||$. & $16.1 \pm 11.1$ & $18.0 \pm 12.6$ & $21.6 \pm 12.8$ & $10.4 \pm 8.9$ & $14.0 \pm 10.8$ & $16.0 \pm 11.7$ & $20.7 \pm 13.9$ \\
\hline $\mathrm{N}$ of $\mathrm{ER}$ visit, mean $\pm \mathrm{SD}$ & $0.4 \pm 0.8$ & $0.8 \pm 1.1$ & $1.1 \pm 2.0$ & $1.8 \pm 2.7$ & $0.5 \pm 1.0$ & $0.9 \pm 1.4$ & $1.3 \pm 2.1$ & $2.4 \pm 4.0$ \\
\hline $\mathrm{N}$ of Inpatient Stays, mean $\pm \mathrm{SD}$ & $0.3 \pm 0.8$ & $0.4 \pm 0.8$ & $0.6 \pm 1.2$ & $0.7 \pm 1.1$ & $0.2 \pm 0.6$ & $0.4 \pm 0.9$ & $0.6 \pm 1.1$ & $0.8 \pm 1.5$ \\
\hline $\mathrm{N}$ of Classes of Medications, mean $\pm \mathrm{SD}$ & $11.7 \pm 6.2$ & $14.3 \pm 7.4$ & $16.3 \pm 8.7$ & $18.4 \pm 8.5$ & $10.5 \pm 6.3$ & $13.5 \pm 7.4$ & $15.2 \pm 8.1$ & $18.7 \pm 9.2$ \\
\hline
\end{tabular}

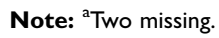

Abbreviations: N, number; SD, standard deviation; MME, morphine milligram equivalent; IQR, interquartile range; ER, emergency room.

with/without abuse" in unadjusted (odds ratio [OR] severe versus no shopping: $2.25,95 \%$ CI: $1.19-4.26)$ and adjusted logistic regression (OR: 2.12, 95\% CI: 1.11-4.04). The unadjusted ORs suggest small numerical increases in risk of "abuse with/without misuse" and "abuse or misuse" among patients in the moderate and severe categories compared to those in the no shopping category. After adjusting for covariates, the strength of the associations for "abuse with/without misuse" and "abuse or misuse" was further attenuated (Table 5).

Social desirability was associated with self-reported abuse and/or misuse but not with shopping behavior objectively determined from patient claims (Table 6). Across the low, median, and high social desirability categories, the percentages of patients in each of the doctor/pharmacy shopping categories were similar, eg, a quarter of patients in the low, median, and high social desirability categories were classified in the "severe shopping" category based on their claims (Table 6). In contrast, higher levels of social desirability were associated with lower frequency of self-reports of abuse and/or misuse. Among patients in the low social desirability category, $9.6 \%, 12.1 \%$, and $15.8 \%$ were considered "abuse with/without misuse", "misuse with/without abuse", and "abuse or misuse", respectively; these proportions were significantly higher than the $1.3 \%, 4.8 \%$, and $5.3 \%$ observed among patients in the high social desirability category (Table 6).

Patients who were not eligible for the survey due to presence of claims indicative of drug/substance abuse were more likely to be classified into the moderate or severe shopping categories based on their claims compared to those who were eligible to participate in the survey. We found that $10.9 \%$ of the patients with claims indicative of drug/substance abuse were classified as severe shoppers, almost four times the corresponding percentage $(2.8 \%)$ among patients who were eligible to participate in the survey.

\section{Discussion}

In this real-world study of doctor/pharmacy shopping in a commercially-insured population, a greater proportion of survey respondents were younger, female and had a psychiatric diagnosis, compared with those who did not respond. This finding is consistent with previous research describing characteristics associated with doctor shopping. ${ }^{8-10}$ Most reasons for visiting multiple doctors and pharmacies were unrelated to abuse or misuse. The most frequent reason for visiting multiple pharmacies was "convenience", followed by "regular pharmacy did not have enough of opioid pain medications", and visiting multiple pharmacies to "get the best prices". Reasons for visiting multiple doctors suggest a lack of perceived need ("doctor does not understand my pain level", "my doctor thinks I may be faking my pain", "needed more opioid pain medications to treat my pain than one doctor would give me") and patients' illness experiences ("see different healthcare providers for different health problems so I ask for an opioid prescription when seeing each healthcare provider"). These reasons are not unlike those identified among patients with other chronic conditions who are doctor shopping. ${ }^{22}$ 
Table 3 Distribution of Patient Characteristics Between Patients Who Completed Survey and Patients Who Did Not

\begin{tabular}{|c|c|c|}
\hline & $\begin{array}{l}\text { Patients Who } \\
\text { Completed } \\
\text { Survey } \\
(n=1085)\end{array}$ & $\begin{array}{l}\text { Patients Who Did } \\
\text { Not Complete } \\
\text { Survey }(n=8996)\end{array}$ \\
\hline $\begin{array}{l}\text { Demographics } \\
\text { Age, Yrs., mean } \pm S D \\
\text { Female, } n, \%\end{array}$ & $\begin{array}{l}44.79 \pm \mid I .27 \\
688,63.4 \mid\end{array}$ & $\begin{array}{l}46.74 \pm 11.75 \\
5058,56.22\end{array}$ \\
\hline $\begin{array}{l}\text { Pain Diagnosis } \\
\text { Abdominal pain, n, \% } \\
\text { Arthritis pain, n, \% } \\
\text { Back pain, n, \% } \\
\text { Chronic pain, n, \% } \\
\text { Headache, n, \% } \\
\text { Neuropathic pain, n, \% }\end{array}$ & $\begin{array}{l}390,35.94 \\
325,29.95 \\
376,34.65 \\
285,26.27 \\
298,27.47 \\
390,35.94\end{array}$ & $\begin{array}{l}2880,32.01 \\
2554,28.39 \\
2720,30.24 \\
1853,20.6 \\
2104,23.39 \\
2880,32.01\end{array}$ \\
\hline $\begin{array}{l}\text { Psychiatric Diagnosis } \\
\text { Alcohol use, n, \% } \\
\text { Anxiety, n, \% } \\
\text { Depression, n, \% }\end{array}$ & $\begin{array}{l}40,3.69 \\
360,33.18 \\
292,26.91\end{array}$ & $\begin{array}{l}309,3.43 \\
2588,28.77 \\
2030,22.57\end{array}$ \\
\hline $\begin{array}{l}\text { Opioid Use During the } \\
\text { I8-Month Period from 7/ } \\
\text { I/I5 to I2/3I/I6 } \\
\mathrm{N} \text { of Opioid } \\
\text { Prescribers, mean } \pm S D \\
\mathrm{~N} \text { of Pharmacies } \\
\text { Opioid Fills, mean } \pm S D \\
\mathrm{~N} \text { of Opioid } \\
\text { Dispensings, median, } \\
\text { IQR } \\
\text { Duration of Opioid } \\
\text { Use, median, IQR } \\
\text { Opioid Daily Dose } \\
\text { (MME/day), median, IQR }\end{array}$ & $\begin{array}{l}3.78 \pm 2.18 \\
2.76 \pm|.4| \\
8.77,7.69 \\
151.33,181.47 \\
40.84,37.14\end{array}$ & $\begin{array}{l}3.4 \pm 2.13 \\
2.53 \pm 1.33 \\
7.75,7.29 \\
130.01,175.76 \\
40.03,34.65\end{array}$ \\
\hline $\begin{array}{l}\text { Use of Other Medications } \\
\text { with Abuse Potential } \\
\text { During the I8-Month } \\
\text { Period from } 7 / 1 / 15 \text { to I2/ } \\
31 / 16 \\
\text { Benzodiazepine, n, \% } \\
\text { Sleep Aid, n, \% } \\
\text { Amphetamines, n, \% }\end{array}$ & $\begin{array}{l}351,32.35 \\
169,15.58 \\
84,7.74\end{array}$ & $\begin{array}{l}2844,31.6 \mid \\
|224,13.6| \\
596,6.63\end{array}$ \\
\hline
\end{tabular}

Abbreviations: $\mathrm{N}$, number; $\mathrm{SD}$, standard deviation; MME, morphine milligram equivalent; $I Q R$, interquartile range.

There were very few patients who reported reasons suggestive of prescription opioid misuse or abuse, such as wanting "more opioid pain medications to get high on"; however, this may be an underestimate, although we tried to control for it. Because of the social stigma associated with opioid abuse and misuse, we obtained a Certificate of
Confidentiality to assure participants of the protection of their confidential information and to alleviate other concerns they may have had. When we explored the impact of social desirability on reporting behaviors associated with abuse and/or misuse, we found that patients with low social desirability were more likely to report abuse and/ or misuse behaviors compared to those with a strong desire to project a socially desirable image. These findings highlight the substantial impact of social desirability on the validity of self-reported substance abuse and are consistent with earlier reports. ${ }^{21,23,24}$

A dose-response relation (trend) was observed showing that patients who visited more prescribers and pharmacies to obtain prescription opioids were more likely to report behaviors attributed to "misuse with/without abuse" and "abuse or misuse". In addition, results from the logistic regression found a significant association between doctor/ pharmacy shopping identified from claims and patient reported misuse. These findings are consistent with those from prior studies that reported a significant association between doctor/pharmacy shopping and prescription opioid abuse, drug-related death, increased risk of overdose, and opioid-related hospital admissions. ${ }^{6,8,9,13}$ These findings are also concordant with those from another study conducted to satisfy the same post-marketing requirement, which found a significant association between doctor/pharmacy shopping identified from the claims data and behaviors suggestive of misuse and/or abuse identified from medical record review. ${ }^{25}$

However, despite the trend and association between doctor/pharmacy shopping and prescription opioid abuse and/or misuse, a vast majority of the "shoppers" did not report abuse or misuse behaviors. Among those in the highest shopping category (severe shoppers), only approximately one out of eight $(12.6 \%)$ reported abuse or misuse behaviors. When further restricted to those in the highest shopping category and lowest social desirability category $(n=100), 19 \%$ of the patients reported abuse or misuse behaviors.

The study has a number of strengths. First, in this population-based survey, we were able to empirically assess the extent to which selection bias may have resulted from the implementation of the inclusion/exclusion criteria, the additional screening criteria at the start of the survey, and from survey non-response. This was achieved by examining the distribution of claims-determined characteristics in these populations that were not included in the survey, eg, between those who completed the survey 
Table 4 Patient Self-Reported Doctor/Pharmacy Shopping Behavior and Reasons for Visiting Multiple Doctors or Pharmacies to Obtain Prescription Opioid Pain Medications

\begin{tabular}{|c|c|c|}
\hline & $\begin{array}{l}\text { Number } \\
\text { Asked }\end{array}$ & $\begin{array}{l}\text { Number with } \\
\text { Accepted } \\
\text { Response }\end{array}$ \\
\hline $\begin{array}{l}\text { In the past year, have you visited }>1 \text { doctor or healthcare provider to get more prescription opioid pain } \\
\text { medication? (Accepted responses: Yes, Not sure) }\end{array}$ & 1085 & 72 \\
\hline $\begin{array}{l}\text { In the past } 3 \text { months, have you visited }>\text { I doctor or healthcare provider to get more prescription opioid } \\
\text { pain medication? (Accepted response: Yes) } \\
\text { In the past } 3 \text { months, why did you visit }>\text { I doctor or healthcare provider to get more prescription } \\
\text { opioid pain medication? (Accepted response: Yes; more than I answer could be chosen) }\end{array}$ & 72 & 15 \\
\hline $\begin{array}{l}\text { I see different healthcare providers for different health problems so I ask for an opioid prescription } \\
\text { when seeing each healthcare provider }\end{array}$ & 15 & 7 \\
\hline I needed more opioid pain medication to treat my pain than I doctor would give me & 15 & 2 \\
\hline I wanted to get more opioid pain medication to get high on & 15 & I \\
\hline I wanted to get more opioid pain medication to sell & 15 & 0 \\
\hline I wanted to get more opioid pain medication to help a friend or relative & 15 & 0 \\
\hline I lost my opioid pain medication & 15 & 0 \\
\hline I wanted to make sure I had enough opioid pain medication in case I needed it & 15 & 2 \\
\hline My insurance, employment or place of residence changed and I had to change my doctor & 15 & 0 \\
\hline My doctor stopped prescribing opioid pain medication & 15 & 3 \\
\hline I was referred to another doctor & 15 & 2 \\
\hline My doctor does not understand my pain level & 15 & 2 \\
\hline My doctor thinks I may be faking my pain & 15 & 2 \\
\hline Other & 15 & 5 \\
\hline $\begin{array}{l}\text { In the past year, have you gone to }>\text { I pharmacy to obtain your prescription opioid pain medication? } \\
\text { (Accepted responses: Yes, Not sure) }\end{array}$ & 1085 & 180 \\
\hline $\begin{array}{l}\text { In the past } 3 \text { months, have you gone to }>\text { I pharmacy to obtain prescription opioid pain medication? } \\
\text { (Accepted response: Yes) } \\
\text { In the past } 3 \text { months, why did you go to >I pharmacy to obtain your prescription opioid pain } \\
\text { medication? (more than I answer could be chosen) }\end{array}$ & 180 & 50 \\
\hline I lost my opioid pain medication & 50 & 0 \\
\hline My prescription was changed to a different dose or medication & 50 & 3 \\
\hline I wanted to make sure I had enough of my opioid pain medication in case I needed it & 50 & I \\
\hline My insurance changed and I had to change my pharmacy & 50 & 5 \\
\hline I needed more opioid pain medication to treat my pain & 50 & I \\
\hline I wanted to get more opioid pain medication and did not want to get caught & 50 & I \\
\hline A pharmacy refused to fill my opioid pain prescription & 50 & 0 \\
\hline I use several different pharmacies for convenience & 50 & 27 \\
\hline My regular pharmacy did not have enough of my opioid pain medication & 50 & 13 \\
\hline I do not want the pharmacist to know how much opioid pain medication I take per month & 50 & I \\
\hline I always try to get the best price so I go to different pharmacies & 50 & 12 \\
\hline Other & 50 & 12 \\
\hline
\end{tabular}

Notes: anly patients who responded "yes" to having visited more than one doctor or pharmacy to obtain prescription opioids in the past 3 months were asked to report their reasons for visiting more than one doctor or pharmacy.

and those who were eligible to be invited to participate in the survey. Second, multiple recruitment strategies were used to increase the response rate, including sending multiple emails and mailed letters. ${ }^{18}$ Third, we used validated methods to identify shopping behavior and opioid misuse and abuse from patients. These validations are part of the same FDA post-marketing requirement for ER/LA opioids and have been published previously. ${ }^{14,25}$

Several considerations should be taken into account in review of these study findings. The study population consisted of patients with commercial insurance that is primarily employment-based. As a result, the 
Table 5 Association Between Claims-Determined Doctor/Pharmacy Shopping Categories and Self-Reported Outcomes of "Abuse with/Without Misuse", “Misuse with/Without Abuse”, and “Abuse or Misuse” (versus No Abuse and No Misuse)

\begin{tabular}{|c|c|c|c|c|c|c|}
\hline $\begin{array}{l}\text { Claims Shopping } \\
\text { Category }\end{array}$ & $\begin{array}{l}\text { Category Total } \\
\mathbf{N}^{\mathrm{a}}\end{array}$ & $\begin{array}{l}\text { Outcome of Interest } \\
\mathbf{N}(\%)\end{array}$ & $\begin{array}{l}\text { Crude } \\
\text { OR }\end{array}$ & $95 \% \mathrm{Cl}$ & $\begin{array}{l}\text { Adjusted } \\
\text { OR }^{\mathbf{b}}\end{array}$ & $95 \% \mathrm{Cl}$ \\
\hline \multicolumn{7}{|l|}{ Abuse } \\
\hline None & 261 & II (4.2) & Reference & & Reference & \\
\hline Minimal & 260 & $12(4.6)$ & 1.10 & $0.48-2.54$ & 0.91 & $0.39-2.13$ \\
\hline Moderate & 256 & $16(6.3)$ & 1.52 & $0.69-3.33$ & 1.18 & $0.52-2.65$ \\
\hline Severe & 253 & $16(6.3)$ & 1.53 & $0.70-3.37$ & 1.14 & $0.50-2.61$ \\
\hline \multicolumn{7}{|l|}{ Misuse } \\
\hline None & 265 & $15(5.7)$ & Reference & & Reference & \\
\hline Minimal & 266 & $18(6.8)$ & 1.21 & $0.60-2.45$ & 1.20 & $0.59-2.45$ \\
\hline Moderate & 262 & $22(8.4)$ & 1.53 & $0.77-3.02$ & 1.50 & $0.76-2.98$ \\
\hline Severe & 269 & 32 (1 1.9$)$ & 2.25 & $1.19-4.26$ & 2.12 & I.II-4.04 \\
\hline \multicolumn{7}{|l|}{ Abuse or Misuse } \\
\hline None & 271 & $21(7.8)$ & Reference & & Reference & \\
\hline Minimal & 271 & $23(8.5)$ & 1.10 & $0.60-2.05$ & 0.98 & $0.52-1.84$ \\
\hline Moderate & 272 & $32(11.8)$ & 1.59 & $0.89-2.83$ & 1.35 & $0.74-2.45$ \\
\hline Severe & 271 & $34(12.6)$ & 1.71 & $0.96-3.03$ & 1.27 & $0.70-2.31$ \\
\hline
\end{tabular}

Notes: a Total for "abuse with/without misuse" analysis excludes individuals with misuse but no abuse; total for "misuse with/without abuse" analysis excludes individuals with abuse but no misuse. 'The following covariates were included in the final-adjusted model: I) abuse with/without misuse: chronic pain, depression, amphetamine use; 2 ) misuse with/without abuse: alcohol use, bipolar, region; 3) abuse or misuse: amphetamine use.

Abbreviations: $\mathrm{N}$, number; $\mathrm{OR}$, odds ratio; $\mathrm{Cl}$, confidence interval.

generalizability of our conclusions is limited to commercially-insured individuals, and may not be generalizable to individuals with government health insurance such as Medicaid and Medicare or individuals with no health insurance. Nonetheless, we feel the findings provide important information on this large commerciallyinsured population.

In addition, for regulatory reasons we were required to exclude patients with claims suggestive of drug or substance abuse. Although this affected less than $1 \%$ of the eligible patient population, exclusion of these patients may have resulted in an underestimation of abuse. While it is true that the exclusion may have introduced a risk of selection bias, it did not confound the observed association. The study is also limited in that the survey could only be completed online and as a result, those without or with limited access to or familiarity with the internet may have been less likely to respond. However, the web-based approach was chosen as previous research has shown that respondents feel more comfortable completing a survey on sensitive topics online compared to over the telephone with an interviewer and the POMAQ was validated in this online setting. ${ }^{26}$ Another limitation of the study is that the 18 -month time window during which doctor/pharmacy shopping was determined from the claims occurred prior to when the outcomes of prescription opioid abuse and/or misuse were ascertained from the patient survey. Also, only those who responded "Yes" to having visited multiple doctors and pharmacies in the past 3 months were asked about the reasons for their behavior. This was done to reduce recall bias but it resulted in a drop in the number of patients who were asked to provide reasons for their shopping behavior.

In summary, in this commercially-insured population, less than $15 \%$ of patients with shopping behavior in the past 3 months reported any reasons attributable to opioid abuse or misuse. The most frequently reported reasons for doctor/pharmacy shopping behavior were unrelated to opioid abuse or misuse, which is concordant with the observation that only a fraction of those in the most severe claims-determined shopping category reported abuse or misuse. Whether this result can be attributed to an actual low level of doctor or pharmacy shopping behavior or to an under-reporting of these behaviors by patients remains an important question for future research. Our findings suggest that, in a commercially-insured population, doctor/pharmacy shopping may not be a good surrogate for opioid abuse or misuse. 
Table 6 Association Between Survey-Determined Social Desirability and Opioid Abuse and/or Misuse and Claims-Determined Doctor/ Pharmacy Shopping Categories, Respectively

\begin{tabular}{|c|c|c|c|c|c|c|c|}
\hline & \multirow{2}{*}{\multicolumn{2}{|c|}{$\begin{array}{l}\text { Low Social Desirability } \\
\mathrm{N}=398\end{array}$}} & \multirow{2}{*}{\multicolumn{2}{|c|}{$\begin{array}{l}\text { Medium Social Desirability } \\
\mathrm{N}=3 \text { I I }\end{array}$}} & \multirow{2}{*}{\multicolumn{2}{|c|}{$\begin{array}{l}\text { High Social Desirability } \\
\mathbf{N}=376\end{array}$}} & \multirow[t]{3}{*}{ P-value } \\
\hline & & & & & & & \\
\hline & $\mathbf{N}$ & $\%$ & $\mathbf{N}$ & $\%$ & $\mathbf{N}$ & $\%$ & \\
\hline \multicolumn{8}{|l|}{ Self-Reported } \\
\hline Abuse with/without misuse & & & & & & & $<0.0001$ \\
\hline Yes & 38 & 9.6 & 12 & 3.9 & 5 & 1.3 & \\
\hline No & 360 & 90.5 & 299 & 96.1 & 371 & 98.7 & \\
\hline Misuse with/without abuse & & & & & & & 0.006 \\
\hline Yes & 48 & 12.1 & 21 & 6.8 & 18 & 4.8 & \\
\hline No & 350 & 88.0 & 290 & 93.3 & 358 & 95.2 & \\
\hline Abuse or misuse & & & & & & & $<0.0001$ \\
\hline Yes & 63 & 15.8 & 27 & 8.7 & 20 & 5.3 & \\
\hline No & 335 & 84.2 & 284 & 91.3 & 356 & 94.7 & \\
\hline \multicolumn{8}{|l|}{ Claims-Based } \\
\hline Doctor/Pharmacy Shopping Category & & & & & & & 0.9730 \\
\hline None & 95 & 23.9 & 81 & 26.1 & 95 & 25.3 & \\
\hline Minimal & 101 & 25.4 & 80 & 25.7 & 90 & 24.0 & \\
\hline Moderate & 102 & 25.6 & 72 & 23.2 & 98 & 26.1 & \\
\hline Severe & 100 & 25.1 & 78 & 25.1 & 93 & 24.7 & \\
\hline
\end{tabular}

Notes: 33rd and 77th percentiles were used to create the categories: low 0-21; medium: 22-23; high: 24 or more.

Abbreviations: $\mathrm{N}$, number.

\section{Acknowledgment}

This project was conducted as part of a Food and Drug Administration (FDA)-required post-marketing study for extended-release and long-acting opioid analgesics and was funded by the Opioid Post-marketing Consortium (OPC) consisting of the following companies at the time of study conduct: Allergan; Assertio Therapeutics, Inc.; BioDelivery Sciences, Inc.; Collegium Pharmaceutical, Inc.; Daiichi Sankyo, Inc.; Egalet Corporation; Endo Pharmaceuticals, Inc.; Hikma Pharmaceuticals USA Inc.; Janssen Pharmaceuticals, Inc.; Mallinckrodt Inc.; Pernix Therapeutics Holdings, Inc.; Pfizer, Inc.; Purdue Pharma, LP. The study was designed in collaboration between HealthCore, Inc. and the OPC and was implemented by HealthCore, Inc.

\section{Disclosure}

JJS, JD, and KH are employees of HealthCore, Inc. JZ and DBE were employees of HealthCore, Inc. at the time of the study. JZ reports a contract with HealthCore at the time of the study and is a current employee of Amgen Inc. DBE is a current employee of Ciconia, Inc. HealthCore received funding from the OPC and from various pharmaceutical companies to conduct the study/research. MSC and DMK are employees of Janssen Research and Development, part of the OPC; Janssen Research and Development markets opioid analgesics.

\section{References}

1. Scholl L, Seth P, Kariisa M, Wilson N, Baldwin G. Drug and opioidinvolved overdose deaths - United States, 2013-2017. MMWR Morb Mortal Wkly Rep. 2018;67(5152):1419-1427. doi:10.15585/mmwr. mm675152e 1

2. Guy GP Jr., Zhang K, Bohm MK, et al. Vital signs: changes in opioid prescribing in the United States, 2006-2015. MMWR Morb Mortal Wkly Rep. 2017;66(26):697-704. doi:10.15585/mmwr.mm6626a4

3. Seth P, Scholl L, Rudd RA, Bacon S. Overdose deaths involving opioids, cocaine, and psychostimulants - United States, 2015-2016. MMWR Morb Mortal Wkly Rep. 2018;67(12):349-358. doi:10.15585/ mmwr.mm6712a1

4. O’Donnell JK, Gladden RM, Seth P. Trends in deaths involving heroin and synthetic opioids excluding methadone, and law enforcement drug product reports, by census region - United States, 2006-2015. MMWR Morb Mortal Wkly Rep. 2017;66(34):897-903. doi:10.15585/mmwr. $\mathrm{mm} 6634 \mathrm{a} 2$

5. Katz N, Panas L, Kim M, et al. Usefulness of prescription monitoring programs for surveillance-analysis of Schedule II opioid prescription data in Massachusetts, 1996-2006. Pharmacoepidemiol Drug Saf. 2010;19(2):115-123. doi:10.1002/pds.v19:2

6. Peirce GL, Smith MJ, Abate MA, Halverson J. Doctor and pharmacy shopping for controlled substances. Med Care. 2012;50(6):494-500. doi:10.1097/MLR.0b013e31824ebd81 
7. Hall AJ, Logan JE, Toblin RL, et al. Patterns of abuse among unintentional pharmaceutical overdose fatalities. JAMA. 2008;300 (22):2613-2620. doi:10.1001/jama.2008.802

8. Cepeda MS, Fife D, Kihm MA, Mastrogiovanni G, Yuan Y. Comparison of the risks of shopping behavior and opioid abuse between tapentadol and oxycodone and association of shopping behavior and opioid abuse. Clin J Pain. 2014;30(12):1051-1056. doi:10.1097/AJP.0000000000000067

9. Jena AB, Goldman D, Weaver L, Karaca-Mandic P. Opioid prescribing by multiple providers in Medicare: retrospective observational study of insurance claims. BMJ. 2014;348:g1393. doi:10.1136/bmj. g1393

10. Wilsey BL, Fishman SM, Gilson AM, et al. Profiling multiple provider prescribing of opioids, benzodiazepines, stimulants, and anorectics. Drug Alcohol Depend. 2010;112(1-2):99-106. doi:10.10 16/j.drugalcdep.2010.05.007

11. Cepeda MS, Fife D, Yuan Y, Mastrogiovanni G. Distance traveled and frequency of interstate opioid dispensing in opioid shoppers and nonshoppers. J Pain. 2013;14(10):1158-1161. doi:10.1016/j.jpain.20 13.04.014

12. Cepeda MS, Fife D, Chow W, Mastrogiovanni G, Henderson SC. Opioid shopping behavior: how often, how soon, which drugs, and what payment method. J Clin Pharmacol. 2013;53(1):112-117. doi:10.1177/0091270012436561

13. Yang Z, Wilsey B, Bohm M, et al. Defining risk of prescription opioid overdose: pharmacy shopping and overlapping prescriptions among long-term opioid users in medicaid. J Pain. 2015;16 (5):445-453. doi:10.1016/j.jpain.2015.01.475

14. Coyne KS, Barsdorf AB, Brooks A, et al. Content validity of the prescription opioid misuse and abuse questionnaire (POMAQ) among chronic pain patients. Value Health. 2017;20(5):A1-A383.

15. Walker AM, Weatherby LB, Cepeda MS, Bradford D, Yuan Y. Possible opioid shopping and its correlates. Clin J Pain. 2017;33 (11):976-982. doi:10.1097/AJP.0000000000000483

16. Cochran WG. Some methods for strengthening the common $\chi 2$ test. Biometrics. 1954;10(4):417-451. doi:10.2307/3001616
17. Armitage P. Tests for linear trends in proportions and frequencies. Biometrics. 1955;11(3):375-386. doi:10.2307/3001775

18. Stephenson JJ, Esposito DB, Gangemi K, et al. Impact of recruitment approach on response rate to an online survey assessing behavior related to the misuse and abuse of prescription opioids. Pharmacoepidemiol Drug Saf. 2018;27(Supplement 2).

19. Smith SM, Dart RC, Katz NP, et al. Classification and definition of misuse, abuse, and related events in clinical trials: ACTTION systematic review and recommendations. Pain. 2013;154(11):22 87-2296. doi:10.1016/j.pain.2013.05.053

20. Reynolds WM. Development of reliable and valid short forms of the marlowe-crowne social desirability scale. J Clin Psychol. 1982;38 (1):119-125. doi:10.1002/(ISSN)1097-4679

21. Johnson T, Fendrich M A validation of the crowne-marlowe social desirability scale. The 57th Annual Meeting of the American Association for Public Opionion Research; 2002.

22. Siu JY. "Seeing a doctor is just like having a date": a qualitative study on doctor shopping among overactive bladder patients in Hong Kong. BMC Fam Pract. 2014;15:27. doi:10.1186/1471-2296-15-27

23. Latkin CA, Edwards C, Davey-Rothwell MA, Tobin KE. The relationship between social desirability bias and self-reports of health, substance use, and social network factors among urban substance users in Baltimore, Maryland. Addict Behav. 2017;73:133-136. doi:10.1016/j.addbeh.2017.05.005

24. Welte JW, Russell M. Influence of socially desirable responding in a study of stress and substance abuse. Alcohol Clin Exp Res. 1993;17 (4):758-761. doi:10.1111/j.1530-0277.1993.tb00836.x

25. Esposito DB, Cepeda MS, Yin R, Chicoat H, Coplan PM, Lanes S. Doctor/pharmacy shopping measures for opioid analgesics and diagnosed abuse and addiction in a US Administrative Database. Pharmacoepidemiol Drug Saf. 2016;25(S3).

26. Kreuter F, Presser S, Tourangeau R. Social desirability bias in CATI, IVR, and web surveys: the effects of mode and question sensitivity. Public Opin Q. 2009;72(5):847-865. doi:10.1093/poq/nfn063
Journal of Pain Research

\section{Publish your work in this journal}

The Journal of Pain Research is an international, peer reviewed, open access, online journal that welcomes laboratory and clinical findings in the fields of pain research and the prevention and management of pain. Original research, reviews, symposium reports, hypothesis formation and commentaries are all considered for publication. The manuscript management system is completely online and includes a very quick and fair peer-review system, which is all easy to use. Visit http:// www.dovepress.com/testimonials.php to read real quotes from published authors. 